\title{
Isospecific polymerization of racemic epoxides: a catalyst system for the synthesis of highly isotactic polyethers $\dagger$
}

\author{
Peter C. B. Widger, Syud M. Ahmed, Wataru Hirahata, Renee M. Thomas, \\ Emil B. Lobkovsky and Geoffrey W. Coates*
}

Received (in Berkeley, CA, USA) 21st December 2009, Accepted 15th February 2010

First published as an Advance Article on the web 22nd March 2010

DOI: $10.1039 / \mathbf{b} 926888 j$

\begin{abstract}
A highly active bimetallic cobalt catalyst system is reported for the polymerization of racemic terminal epoxides to yield isotactic polyethers.
\end{abstract}

Stereoregular polymers often display superior mechanical and thermal properties compared to their atactic analogues. ${ }^{1}$ Polyethers are an important class of polymers with industrial and biological applications. ${ }^{2}$ Much progress has been made in controlling the regiochemistry and molecular weight of polyethers, ${ }^{3}$ but controlling the stereochemistry of polyethers synthesized from racemic epoxides remains a challenge. ${ }^{4}$ Previous isoselective polymerization systems for racemic epoxides produced mixtures of atactic and isotactic materials, or generated only moderately isotactic polymers. ${ }^{5} \mathrm{We}$ previously reported a highly active and isoselective cobalt catalyst for the polymerization of racemic propylene oxide (rac-PO). ${ }^{6}$ Using the information gained by studying the mechanism of this catalyst, ${ }^{7}$ we have recently designed a highly active and enantioselective polymerization catalyst system that exhibits greater substrate scope. It consists of a bimetallic cobalt complex (1) and a bis(triphenylphosphine)iminium (PPN) acetate cocatalyst (4, Scheme 1$)$. This system selectively polymerizes one enantiomer of racemic terminal epoxides to produce highly isotactic polyethers and enantiopure epoxides. ${ }^{8}$ Unfortunately, this limits the theoretical maximum yield of polymer at $c a$. $50 \%$ unless the racemic form of $\mathbf{1}$ is used. Attempts to synthesize rac-1 (equimolar mixture of $\left(R_{4} S\right)-\mathbf{1}$ and $\left.\left(S_{4} R\right)-1\right)$ from racemic starting materials produced inseparable diastereomers, which led us to develop a new catalyst that is active and isoselective while being derived from inexpensive racemic and/or achiral starting materials.

Insight into the origin of enantioselectivity of $\mathbf{1}$ was gained through the reactivity of the diastereomeric cobalt complex $\mathbf{2}$, which possesses all $S$ stereochemistry. When activated with PPN compound 4, complex $\mathbf{2}$ displayed lower activity than $\mathbf{1}$ for the polymerization of neat rac-PO $\left(T_{\mathrm{rxn}}=0{ }^{\circ} \mathrm{C}\right)$, but preferred the same enantiomer $(S)$ with a $k_{S} / k_{R}$ selectivity factor of $210 .^{9}$ This result confirmed that the stereochemistry of the binaphthol linker determines which enantiomer of

Department of Chemistry and Chemical Biology, Baker Laboratory, Cornell University, Ithaca, NY 14853-1301, USA.

E-mail: gc39@cornell.edu; Fax: +1607-255-4137;

Tel: + 1 607-255-5447

$\dagger$ Electronic supplementary information (ESI) available: Experimental procedures and crystallographic details. CCDC 759359. For ESI and crystallographic data in CIF or other electronic format see DOI: $10.1039 / \mathrm{b} 926888 \mathrm{j}$
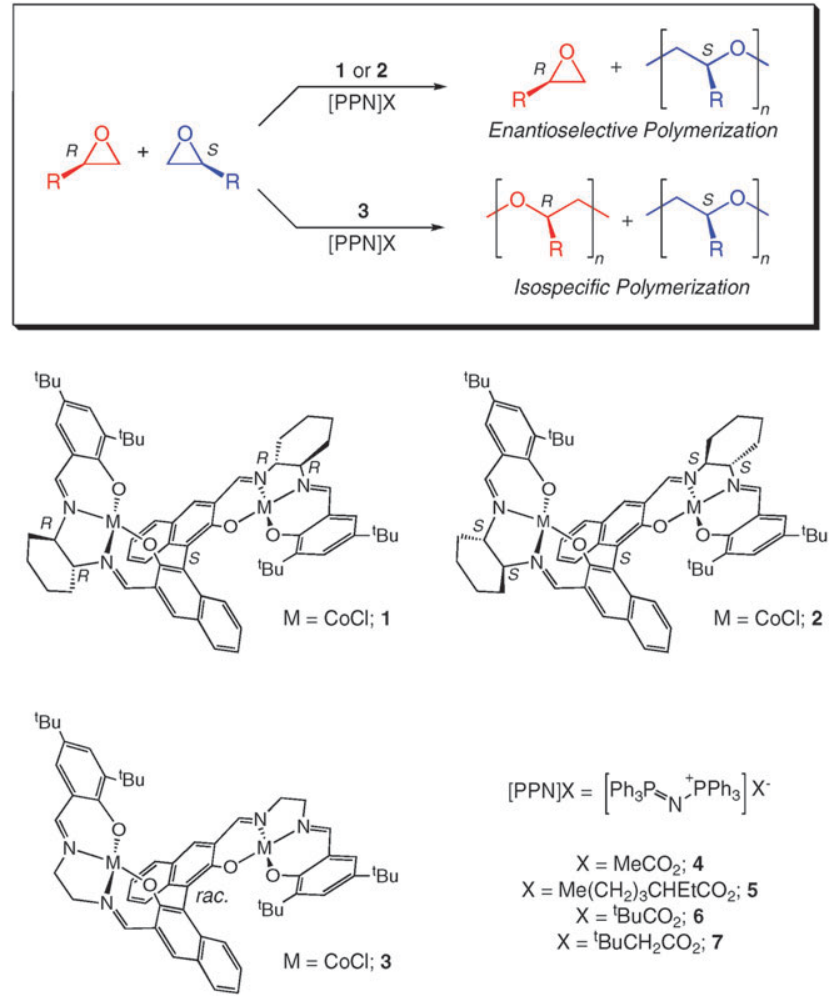

Scheme 1 Enantioselective and isospecific polymerization of racemic epoxides using bimetallic cobalt catalysts.

monomer is enchained, possibly allowing simplification of $\mathbf{1}$ and 2 by removal of the chiral diamine linker.

Having determined that the axial chirality of the binaphthol linker is responsible for the stereoselectivity of the polymerization, we synthesized complex 3, which incorporated ethylene diamine and a rac-binaphthol linker. $\dagger$ All attempts at crystallizing $\mathbf{3}$ from non-coordinating solvents were unsuccessful, however crystals were grown from pyridine and toluene giving black needles that were analyzed by single crystal X-ray diffraction. Fig. 1 shows the structure of $\mathbf{3}$ with hydrogens omitted and pyridine ligands truncated for clarity. Two pyridines are bound to each cobalt center displacing the chlorides giving a pseudo $C_{2}$ symmetric complex. ${ }^{10}$ The Co-Co distance is $6.774 \AA$ and the endo naphthol-naphthol dihedral angle is $84.3^{\circ}$.

Initial polymerizations of neat rac-PO using catalyst 3 and cocatalyst $4(3 / 4)$ (Table 1, entry 1 ) were less active in comparison with system $\mathbf{1} / \mathbf{4}$, yielding regioregular poly(propylene oxide) 


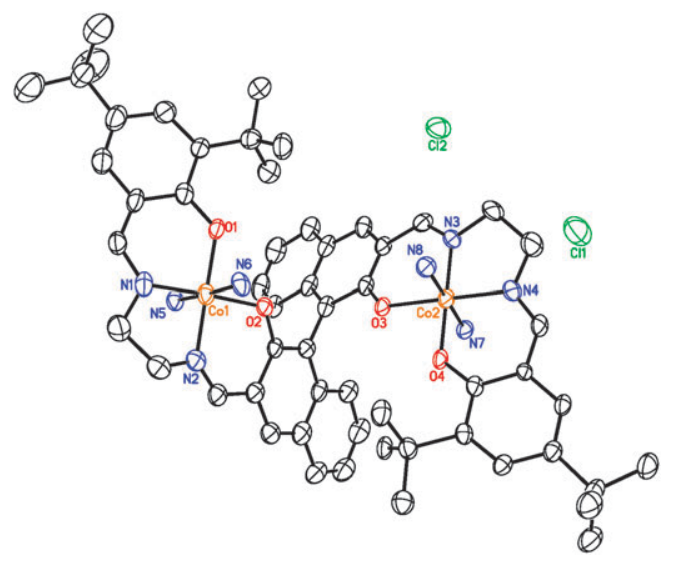

Fig. 1 Molecular structure of the tetrapyridine adduct of 3 crystallized from pyridine and toluene (hydrogen atoms omitted and pyridine ligands truncated for clarity; carbon atoms are unlabelled). Thermal ellipsoids are at the $30 \%$ probability level.

(PPO) with moderate isotacticity $(67 \% \mathrm{~mm}$ triad content). Analysis of the polymer tacticity using ${ }^{13} \mathrm{C}$ NMR spectroscopy showed stereoerrors ${ }^{11}$ indicative of enantiomorphic site control. $\dagger$

In an effort to increase the activity of $\mathbf{3}$, we modified the anions of PPN salts, which have been found to have dramatic effects on the activity and selectivity of $\mathrm{PO} / \mathrm{CO}_{2}$ copolymerizations. ${ }^{12} \mathrm{We}$ investigated the use of cocatalyst $\mathbf{5}$, and found that when combined with $\mathbf{3}$ the rate of polymerization dramatically increased. When run neat, the reaction exothermed vigorously; thus, further polymerizations were conducted in toluene at $0{ }^{\circ} \mathrm{C}$ for $5 \mathrm{~min}$. Cocatalyst 5 also dramatically increased the selectivity, producing highly isotactic PPO with $96 \% \mathrm{~mm}$ triad content (Table 1 , entry 2 ).

Two bulky achiral cocatalysts 6 and 7 were synthesized to determine if the enhanced selectivity resulting from $\mathbf{5}$ originated from its chirality or increased sterics. Both $\mathbf{6}$ and 7 were very active for the polymerization of PO in the presence of $\mathbf{3}$ and produced highly isotactic polymer (Table 1, entries 3 and 4). ${ }^{13}$ Cocatalyst 6 produced the highest rates and isoselectivity (Fig. 2) when combined with 3. Thus 6 was used in all subsequent polymerizations. The role of the cocatalyst anion in the polymerization is currently unclear. We propose that the cocatalyst anion coordinates to one cobalt center. An epoxide molecule then coordinates to the adjacent cobalt center inside the catalyst cleft, and is ring-opened by a nucleophile $(\mathrm{Cl}$ or carboxylate, depending on initial position of $\mathrm{Cl}$ ligands) to initiate polymerization (Scheme 2). Subsequent ring-opening events occur alternatively at the adjacent cobalt centers to

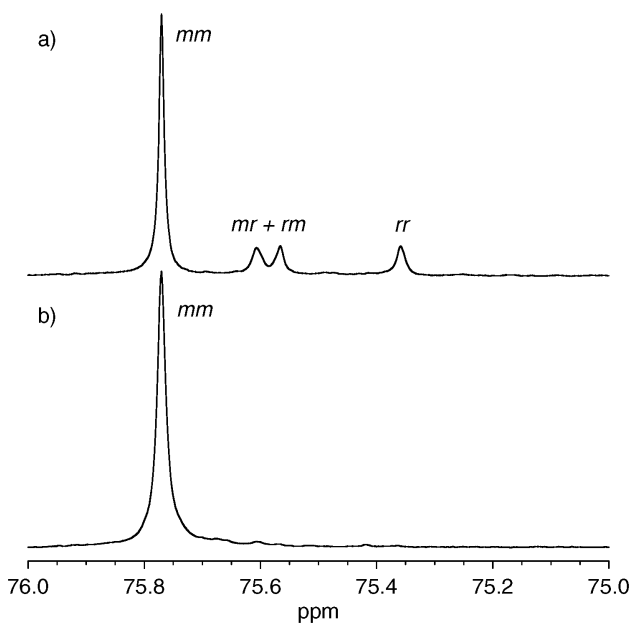

Fig. 2 Methine regions of the ${ }^{13} \mathrm{C}$ NMR spectra of PPO produced using (a) catalyst $\mathbf{3}$ and cocatalyst $\mathbf{4}$; (b) catalyst $\mathbf{3}$ and cocatalyst $\mathbf{6}$.

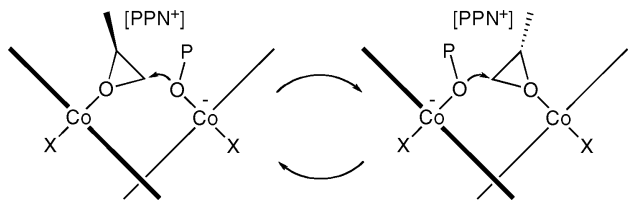

Scheme 2 Proposed mechanism of polymerization $(\mathrm{P}=$ polymer chain; $\mathrm{X}=\mathrm{Cl}$ or carboxylate).

create the polymer chain. Our working hypothesis is that the increased bulk of $\mathbf{6}$ compared to $\mathbf{4}$ prevents its carboxylate from entering the catalyst cleft, favoring its position anti to the epoxide/polymer alkoxide. ${ }^{14}$

The new catalyst system (3/6) was screened for the polymerization of a number of terminal epoxides possessing aliphatic, ether, vinyl, aromatic and fluorinated side chains (Table 2). Catalyst system (3/6) produced racemic, highly isotactic polyethers at rapid rates. Nearly all polymers had molecular weights significantly higher than the theoretical molecular weights calculated from one polymer chain per metal complex. This is consistent with $\mathbf{3}$ being a mixture of chloride diastereomers, of which only a fraction are catalytically active. ${ }^{8}$ The molecular weight distributions $\left(M_{\mathrm{w}} / M_{\mathrm{n}}\right)$ are $c a .2$ consistent with a single site catalyst.

Propylene oxide and 1-butene oxide were both polymerized at rapid rates with high isoselectivities to polymers with high molecular weight (Table 2, entries 1 and 2). Phenyl glycidyl ether was polymerized very rapidly and displayed very high isotacticity (entry 3). Butadiene monoepoxide was polymerized rapidly, but had moderate isotacticity (entry 4). Poly(butadiene

Table 1 Polymerization of racemic propylene oxide with $\mathbf{3}$ and various co-catalysts ${ }^{a}$

\begin{tabular}{|c|c|c|c|c|c|c|c|}
\hline Entry & {$[\mathrm{PPN}] \mathrm{X}$} & $t_{\mathrm{rxn}} / \mathrm{min}$ & $T_{\mathrm{rxn}} /{ }^{\circ} \mathrm{C}$ & Conv. $^{b}(\%)$ & $M_{\mathrm{n}}^{c} / \mathrm{kg} \mathrm{mol}^{-1}$ & $M_{\mathrm{w}} / M_{\mathrm{n}}^{c}$ & {$[m m]^{d}(\%)$} \\
\hline $1^{e}$ & 4 & 1440 & 20 & 29 & 57 & 2.2 & 67 \\
\hline 2 & 5 & 5 & 0 & 43 & 153 & 1.7 & 96 \\
\hline 3 & 6 & 5 & 0 & 55 & 134 & 1.8 & 97 \\
\hline 4 & 7 & 5 & 0 & 7 & 47 & 3.6 & 96 \\
\hline
\end{tabular}

${ }^{a}$ General conditions: [3] : [PPN]X $=1: 2,[3]:[\mathrm{PO}]=1: 4000$, and [PO] $=2 \mathrm{M}$ in toluene. ${ }^{b}$ Determined by ${ }^{1} \mathrm{H}$ NMR spectroscopy.

${ }^{c}$ Determined by gel-permeation chromatography calibrated with polystyrene standards in $1,2,4-\mathrm{Cl}_{3} \mathrm{C}_{6} \mathrm{H}_{3}$ at $140{ }^{\circ} \mathrm{C}$. ${ }^{d}[\mathrm{~mm}]$ triad content determined by ${ }^{13} \mathrm{C}$ NMR spectroscopy. ${ }^{e}$ Reaction run in neat $\mathrm{PO},[3]:[\mathrm{PO}]=1: 2000$. 
Table 2 Screening of racemic epoxides for isoselective polymerization catalyzed by system $(\mathbf{3} / \mathbf{6})^{a}$

\begin{tabular}{llclllr}
\hline Entry & $\begin{array}{l}\text { Epoxide } \\
\text { subs. (R) }\end{array}$ & $\begin{array}{l}t_{\mathrm{rxn}} / \\
\mathrm{min}\end{array}$ & $\begin{array}{l}\text { Conv. } \\
(\%)\end{array}$ & $\begin{array}{l}M_{\mathrm{n}}{ }^{c} / \\
\mathrm{kg} \mathrm{mol}^{-1}\end{array}$ & $\begin{array}{l}M_{\mathrm{w} /} / \\
M_{\mathrm{n}}{ }^{c}\end{array}$ & $\begin{array}{l}{[\mathrm{mm}]^{d}} \\
(\%)\end{array}$ \\
\hline 1 & $\mathrm{Me}$ & 5 & 55 & 134 & 1.8 & 97 \\
2 & $\mathrm{Et}$ & 5 & 60 & 239 & 1.5 & 97 \\
3 & $\mathrm{CH}_{2} \mathrm{OPh}$ & 1 & 89 & 328 & 1.4 & $\geq 97$ \\
4 & $\mathrm{CH}=\mathrm{CH}_{2}$ & 10 & 46 & 212 & 1.5 & 92 \\
5 & $\mathrm{Ph}$ & 45 & 23 & 77 & 1.9 & $\geq 97$ \\
6 & $\mathrm{CF}_{3}$ & 90 & 32 & $20^{e}$ & $13^{e}$ & $\geq 97$
\end{tabular}

${ }^{a}$ General conditions: [3] : [6] $=1: 2,[3]:$ [epoxide] $=1: 4000$, $T_{\text {rxn }}=0{ }^{\circ} \mathrm{C}$ and [epoxide] $=2 \mathrm{M}$ in toluene. ${ }^{b}$ Determined by ${ }^{1} \mathrm{H}$ NMR spectroscopy. ${ }^{c}$ Determined by gel-permeation chromatography calibrated with polystyrene standards in $1,2,4-\mathrm{Cl}_{3} \mathrm{C}_{6} \mathrm{H}_{3}$ at $140{ }^{\circ} \mathrm{C} .{ }^{d}[\mathrm{~mm}]$ triad content determined by ${ }^{13} \mathrm{C}$ NMR spectroscopy. ${ }^{e}$ Determined by gel-permeation chromatography calibrated with poly(methyl methacrylate) in $N, N$-dimethylformamide containing $0.01 \mathrm{M}$ lithium nitrate and $1 \%$ formic acid at $35^{\circ} \mathrm{C}$.

Table 3 Quantitative conversion of racemic epoxides to isotactic polyethers catalyzed by system $(\mathbf{3} / \mathbf{6})^{a}$

\begin{tabular}{llclllr}
\hline Entry & $\begin{array}{l}\text { Epoxide } \\
\text { subs. (R) }\end{array}$ & $t_{\mathrm{rxn}} / \mathrm{h}$ & $\begin{array}{l}\text { Conv. }^{b} \\
(\%)\end{array}$ & $\begin{array}{l}M_{\mathrm{n}}{ }^{c} / \\
\mathrm{kg} \mathrm{mol}^{-1}\end{array}$ & $\begin{array}{l}M_{\mathrm{w} /} / \\
M_{\mathrm{n}}{ }^{c}\end{array}$ & $\begin{array}{l}{[\mathrm{mm}]^{d}} \\
(\%)\end{array}$ \\
\hline 1 & $\mathrm{Me}$ & 1 & $>99$ & 107 & 1.8 & 97 \\
2 & $\mathrm{Et}$ & 1 & $>99$ & 163 & 1.6 & 97 \\
3 & $\mathrm{CH}_{2} \mathrm{OPh}$ & 0.08 & $>99^{e}$ & 278 & 1.3 & $\geq 97$ \\
4 & $\mathrm{CH}=\mathrm{CH}_{2}$ & 1 & $>99$ & 135 & 2.1 & 92 \\
5 & $\mathrm{Ph}$ & 15 & $>99$ & 59 & 2.0 & $\geq 97$ \\
6 & $\mathrm{CF}_{3}$ & 6 & $>99$ & $85^{f}$ & $6.9^{f}$ & $\geq 97$
\end{tabular}

${ }^{a}$ General conditions: [3] : [6] $=1: 2,[3]:$ [epoxide] $=1: 1000$, $T_{\text {rxn }}=0{ }^{\circ} \mathrm{C}$ and [epoxide] $=0.6 \mathrm{M}$ in toluene. ${ }^{b}$ Determined by ${ }^{1} \mathrm{H}$ NMR spectroscopy. ${ }^{c}$ Determined by gel-permeation chromatography calibrated with polystyrene standards in $1,2,4-\mathrm{Cl}_{3} \mathrm{C}_{6} \mathrm{H}_{3}$ at $140{ }^{\circ}$ C. ${ }^{d}[\mathrm{~mm}]$ triad content determined by ${ }^{13} \mathrm{C}$ NMR spectroscopy. ${ }^{e}$ Determined gravimetrically. ${ }^{f}$ Determined by gel-permeation chromatography calibrated with poly(methyl methacrylate) in $N, N$ dimethylformamide containing $0.01 \mathrm{M}$ lithium nitrate and $1 \%$ formic acid at $35^{\circ} \mathrm{C}$.

monoepoxide) posses a pendant olefin potentially allowing for functionalization. Styrene oxide was polymerized at a reasonable rate with high tacticity (entry 5). Trifluoropropylene oxide was polymerized slowly but the resulting polymer displayed high isotacticity (entry 6). The polymer was insoluble in traditional GPC solvents and had to be chromatographed using DMF, making molecular weight comparisons difficult. Racemic epoxides were quantitatively polymerized to racemic isotactic polyether at slightly higher loading of catalyst and higher dilution as shown in Table 3. The rates of polymerization were quite rapid, and all polymers displayed high isotacticity.

In conclusion, we have shown that the axial chirality of the binaphthol linker in our bimetallic cobalt catalysts is responsible for enantioselectivity of monomer enchainment in epoxide polymerization. We synthesized a new racemic bimetallic cobalt complex (3) that can quantitatively polymerize racemic terminal epoxides to highly isotactic polyethers.
We have also synthesized a new cocatalyst (6) that increased the rate and selectivity of $\mathbf{3}$. The catalyst system (3/6) displays high activity, surpassing that of system $(\mathbf{1} / \mathbf{4})$. Future work will focus on understanding the mechanism of this polymerization system and the origin of the effect of the cocatalyst on activity and selectivity.

We acknowledge the NSF (CHE-0809778) and the King Abdullah University of Science and Technology (KAUST; Award No. KUS-C1-018-02) for support of this research. The authors are grateful for the help of T. Mourey at Kodak for polymer molecular weight determination.

\section{Notes and references}

1 Stereoselective Polymerization with Single Site Catalysts, ed. L. S. Baugh and J. M. Canich, CRC Press, Boca Raton, 2008, pp. 1-9.

2 (a) Encyclopedia of Chemical Technology, ed. J. I. Kroschwitz and M. Howe-Grant, Wiley, Chichester, 1993, vol. 8, pp. 1079-1093; (b) D. Wilms, S. Stiriba and H. Frey, Acc. Chem. Res., 2010, 43, $129-141$.

3 For some recent examples of discrete catalysts for epoxide polymerization, see: (a) M. Gervais, A. Labbé, S. Carlotti and A. Deffieux, Macromolecules, 2009, 42, 2395-2400; (b) J. Raynaud, C. Absalon, Y. Gnanou and D. Taton, J. Am. Chem. Soc., 2009, 131, 3201-3209; (c) L. Tang, E. P. Wasserman, D. R. Neithamer, R. D. Krystosek, Y. Cheng, P. C. Price, Y. He and T. J. Emge, Macromolecules, 2008, 41, 7306-7315; (d) A. Labbé, S. Carlotti, C. Billouard, P. Desbois and A. Deffieux, Macromolecules, 2007, 40, 7842-7847; (e) J. Allgaier, S. Willbold and T. Chang, Macromolecules, 2007, 40, 518-525; $(f)$ I. Kim, J.-T. Ahn, C. S. Ha, C. S. Yang and I. Park, Polymer, 2003, 44, 3417-3428; $(g)$ W. Braune and J. Okuda, Angew. Chem., Int. Ed., 2003, 42, 64-68; (h) D. Chakraborty, A. Rodriguez and E. Y.-X. Chen, Macromolecules, 2003, 36, 5470-5481; (i) O. Rexin and R. Mülhaupt, Macromol. Chem. Phys., 2003, 204, 1102-1109; (j) B. Eßwein, N. M. Steidl and M. Möller, Macromol. Rapid Commun., 1996, 17, 143-148.

4 W. Kuran, Prog. Polym. Sci., 1998, 23, 919-992.

5 For a review, see: H. Ajiro, S. D. Allen and G. W. Coates, Discrete Catalysts for Stereoselective Epoxide Polymerization, in ref. 1, ch. 24, pp. 627-644.

6 K. L. Peretti, H. Ajiro, C. T. Cohen, E. B. Lobkovsky and G. W. Coates, J. Am. Chem. Soc., 2005, 127, 11566-11567.

7 H. Ajiro, K. L. Peretti, E. B. Lobkovsky and G. W. Coates, Dalton Trans., 2009, 8828-8830.

8 (a) W. Hirahata, R. M. Thomas, E. Lobkovsky and G. W. Coates, J. Am. Chem. Soc., 2008, 130, 17658-17659; (b) R. M. Thomas, R. C. Jeske, W. Hirahata and G. W. Coates, manuscript in preparation.

9 This is in contrast to previous catalytic systems using $(S, S)$ (salcy)CoOAc which have shown selectivity for the hydrolysis of $R$-PO: M. Tokunaga, J. F. Larrow, F. Kakiuchi and E. N. Jacobsen, Science, 1997, 277, 936-938.

10 Pyridine was also used for NMR analyses of cobalt(III) complexes giving diamagnetic spectra: S. Kemper, P. Hrobárik, M. Kaupp and N. E. Schlörer, J. Am. Chem. Soc., 2009, 31, 6641.

11 F. C. Schilling and A. E. Tonelli, Macromolecules, 1986, 19, 1337-1343.

12 C. T. Cohen, T. Chu and G. W. Coates, J. Am. Chem. Soc., 2005, 127, 10869-10878.

13 A sample of enantiopure 3 synthesized from $S$-binaphtholenchained $S$-PO with a $k_{S} / k_{R}$ selectivity factor of 160 when combined with 6 at $0{ }^{\circ} \mathrm{C}$.

14 L. P. C. Nielsen, C. P. Stevenson, D. G. Blackmond and E. N. Jacobsen, J. Am. Chem. Soc., 2004, 126, 1360-1362. 